\title{
Effect of a Crude Sulfated Polysaccharide from Halymenia floresia (Rhodophyta) on gastrointestinal smooth muscle contractility
}

\author{
José Ronaldo Vasconcelos Graça ${ }^{1}$, Mirna Marques Bezerra ${ }^{1}$, Vilma Lima ${ }^{2}$, José Ariévilo \\ Gurgel Rodrigues ${ }^{3}$, Diego Levi Silveira Monteiro ${ }^{1}$, Ana Luíza Gomes Quinderé ${ }^{4}$, Rodrigo \\ César das Neves Amorim ${ }^{4}$, Regina Célia Monteiro de Paula ${ }^{5}$ and Norma Maria Barros \\ Benevides $^{3,4^{*}}$ \\ ${ }^{1}$ Faculdade de Medicina; Universidade Federal do Ceará; Av. Comandante Maurocélio Rocha Pontes, 100; \\ Campus Sobral - CE - Brasil. ${ }^{2}$ Departamento de Odontologia, Faculdade de Farmácia e Enfermagem; \\ Universidade Federal do Ceará; Rua Monsenhor Furtado s/n; Fortaleza - CE - Brasil. ${ }^{3}$ Programa de Pós \\ graduação em Biotecnologia, Rede Nordeste de Biotecnologia; Universidade Estadual do Ceará; Av. Paranjana, \\ 1700; Fortaleza - CE - Brasil. ${ }^{4}$ Departamento de Bioquímica e Biologia Molecular; Universidade Federal do \\ Ceará; Av. Mister Hull s/ $n$; Fortaleza - CE - Brasil. ${ }^{5}$ Departamento de Química Orgânica e Inorgânica; \\ Universidade Federal do Ceará; Av. Mister Hull s/n; Fortaleza - CE - Brasil
}

\begin{abstract}
The aim of this work was to study the effect of Halymenia floresia $(\mathrm{Hf})$ on duodenum contractility, and on experimental protocols of gastric compliance $(G C)$ in rats. Fraction Hf2s exhibited a concentration-dependent myocontractile effect $\left(E C_{50} 12.48 \mu \mathrm{g} / \mathrm{ml}\right)$, and an inhibitory effect after consecutive washing. The contractile response promoted by Hf2s in the duodenum strips was completely inhibited by verapamil, and the effects were prevented in the presence of Ca2+-free medium. The pretreatment with atropine prevented the Hf2s myocontractile effect. Hf2s was also capable to decrease the GC (from $3.8 \pm 0.06$ to $3.4 \pm 0.13 \mathrm{ml}, P<0.05$ ), which did not return to basal levels after more 50 min of observation. These results indicated that the algal polysaccharide possessed in vitro and in vivo gastrointestinal effects.
\end{abstract}

Key words: Halymenia floresia, sulfated polysaccharides, gut motility

\section{INTRODUCTION}

Seaweeds are traditionally consumed in the Orient as part of the daily diet. Some researchers describe them as the foods without toxic and/or antinutritional effects, being thus considered as alternative sources for food industry (Campo et al.,
2009). These are known to possess good nutritional value as source of proteins, carbohydrate, minerals, carotenoids and vitamins (Marinho-Soriano, 2006; Pires et al., 2008). Marine algae are also considered as low-calorie food, leading to reduction in body weight control and total cholesterol and LDL-C, and prevention

*Author for correspondence: nmbb@ufc.br 
of gastrointestinal diseases when consumed (Carvalho et al., 2009). However, there are only a few carried out so far describing their composition. They contain polysaccharides that may bind to metals through their carbonyl, hydroxyl or sulfated groups, and that can also exhibit toxic properties (Langwinski and Patiño, 2001). According to Andrade et al. (2010), the brown algae Padina gymnospora, when exposed to heavy metal-contaminated environments, changes its polysaccharide content. As a result, this species overproduces cell wall polysaccharides as a defense mechanism.

Sulfated polysaccharides (SPs) make up a group of biopolymers that occur in a great variety of marine organisms (Stephen, 1995; Hayashi et al., 1996; Mourão and Pereira, 1999; Aquino et al., 2005; Pomin and Mourão, 2008; Robic et al., 2009; Rodrigues et al., 2009a; Mestechkina and Shcherbukhin, 2010; Rodrigues et al., 2010). In red seaweed, SPs are known as sulfated galactans, and are found in carrageenans and agarans (Melo et al., 2002; Marinho-Soriano, 2006; Pomin and Mourão, 2008; Campo et al., 2009; Silva et al., 2010; Rodrigues et al., 2011a). These highly charged macromolecules (presence of sulfate groups) exhibit chemical structures of complex and heterogeneous nature, playing an important role in ionic, mechanical and osmotic functions, and are constituents of the extracellular matrix of marine algae (Kloareg and Quatrano, 1988). Seaweed SPs are also considered non-toxic, nondependent, low cost, and do not leave any residue. They do not cause negative impacts to the environment and to the consumer (Becherè, 2000; Campo et al., 2009). Nevertheless, the adverse effect level of SPs depend the administered dose (Li et al., 2005).

In recent years, SPs have been extensively studied as anticoagulant and antithrombotic agents (Farias et al., 2000; Matsubara et al., 2001; Mourão, 2004; Pereira et al., 2005; Pushpamali et al., 2008; Azevedo et al., 2009; Rodrigues et al., 2009a; Rodrigues et al., 2009b; Rodrigues et al., 2010; Mestechkina and Shcherbukhin, 2010; Rodrigues et al., 2011a). Their biological actions suggest that each SP may be dependent of a structural requirement (Mourão and Pereira, 1999; Pereira et al., 2005). SPs are reported to have a large number of biological properties. For example, a highly sulfated heteropolysaccharide (known as ulvan), extracted from the green marine algae Ulva pertusa exhibited strong in vitro antioxidant activity (Zhang et al., 2003). Talarico et al. (2004) reported that the sulfated galactans obtained from red seaweeds Gymnogongrus griffithsiae and Cryptonemia crenulata showed antiviral properties against four serotypes of dengue virus in different host cell types. Fonseca et al. (2008), investigating the effects of a SP isolated from Gelidium crinale (Rhodophyta) on a venous thrombosis model, reported that it could be considered as a valuable tool for better comprehension of the physiopathology of thromboembolic diseases. A SP isolated from the red marine algae Champia feldmannii demonstrated to be an important edematogenic agent (Assreuy et al., 2008). When its in vitro and in vivo antitumor properties were evaluated, the results showed that the compound was also capable of inhibiting the development of sarcoma 180 tumor, suggesting an immunostimulant. This molecule induced a discreet hyperplasia of lymphoid follicles of the spleen white pulp of treated mice. Histopathological analysis of liver and kidney showed that both organs were also moderately affected by $C$. feldmannii SP treatment (Lins et al., 2009). Recently, a crude polysaccharide from the cell-wall from Turbinaria ornata (Phaeophyta) presented in vivo anti-inflammatory activities (Ananthi et al., 2010).

Halymenia floresia (Clemente) C. Agardh is a red marine algae belonging to the Halymeniaceae family, found at Mucuripe Beach, coast of Ceará State, Brazil. Morales et al. (2006) identified a toxic effect in the antibacterial activity of secondary metabolites extracted from this species. Recently, the $H$. floresia SPs have been extracted and studied as anticoagulant agents (Amorim et al., 2011; Rodrigues et al., 2011b). Based on the fact that no biological study about their effects in vivo and in vitro in models of gastrointestinal has, to our best knowledge, yet been reported, we decided to investigate the effects of a crude soluble SP fraction of this species on rat duodenum contractility in vitro, and in gastrointestinal property in vivo.

\section{MATERIAL AND METHODS}

\section{Animals}

Male Wistar rats (250-350g) from the Animal House of the Federal University of Ceará were 
randomly selected and kept under a 12-h light/dark cycle, in temperature-controlled rooms, and were fed with water and food ad libitum. All the procedures and animal treatments used in this study were approved by the Institutional Animal Care and Used Committee of the Federal University of Ceará, Fortaleza-CE, Brazil, in accordance with the international guidelines (NIH publications No. 85-23, revised 1985), previously approved by the $125 / 07$ protocol.

\section{Drugs and reagents}

The reagents used in the study included $\mathrm{NaCl}$, $\mathrm{KCl}, \mathrm{MgCl}_{2}, \mathrm{CaCl}_{2}, \mathrm{NaH}_{2} \mathrm{PO}_{4}, \mathrm{NaHCO}_{3}$, glucose, ketamine, xylazine (Vetec Química Farm. Ltda, São Paulo, Brazil), atropine, verapamil, urethane (Sigma Chemical Co., St. Louis, MO, U.S.A or Sigma Aldrich Chemie, Steinheim, Germany).

\section{Extraction of SPs}

The $H$. floresia SPs were successively extracted as described elsewhere (Amorim et al., 2011). Crude fractions Hf1s, Hf2s and Hf3s were obtained, respectively, at different temperatures 25 or $80^{\circ} \mathrm{C}$ (twice). Briefly, the algae were submitted to mechanical stirring for $24 \mathrm{~h}$ at room temperature in water at $1.5 \%(\mathrm{w} / \mathrm{v})$. The residue was removed by centrifugation $\left(5.000 \times g\right.$ for $15 \mathrm{~min}$ at $\left.4^{\circ} \mathrm{C}\right)$. The supernatant was precipitated with absolute $\mathrm{EtOH}(1: 3, \mathrm{v} / \mathrm{v})$, centrifuged, re-dissolved in distilled water, dialyzed against water, freeze-dried and denominated Hf1s. The algal residue was reextracted but this time at $80^{\circ} \mathrm{C}$ for $4 \mathrm{~h}$, followed by centrifugation under the same conditions. The hot extraction was repeated once more, using the second extraction residue. The supernatants were precipitated with absolute EtOH (1:3, v/v), and denominated Hf2s and Hf3s for the second and third extractions, respectively.

\section{Agarose gel electrophoresis}

The crude fractions Hf1s, Hf2s and Hf3s were analyzed by $0.5 \%$ agarose gel electroforesis according to Dietrich and Dietrich (1976). Samples of each crude SP fraction $(30 \mu \mathrm{g})$ were applied to a gel and run for $1 \mathrm{~h}$ at $110 \mathrm{~V}$ in $0.05 \mathrm{M}$ 1.3 diaminopropane-acetate buffer ( $\mathrm{pH} 9.0)$. SP on gel were fixed with $0.1 \% \quad \mathrm{~N}$-cetyl- $\mathrm{N}-\mathrm{N}-\mathrm{N}$ trimethylammonium bromide solution. After $12 \mathrm{~h}$, the gel was dried and stained with $0.1 \%$ toluidine blue and discolored with an acetic acid: absolute ethanol: distillated water solution (0.1:0.45:0.45).

\section{Molar mass distribution}

The peak molar masses $\left(M_{\mathrm{pk}}\right)$ were estimated by gel permeation chromatography (GPC) with a Shimadzu equipment at room temperature using an Ultrahydrogel linear column $(7.8 \times 300 \mathrm{~mm})$, flow of $0.5 \mathrm{~mL} / \mathrm{min}, 0.5 \%$ polysaccharide concentration (Hf1s, Hf2s and $\mathrm{Hf} 3 \mathrm{~s}$ ) and $0.1 \mathrm{M} \mathrm{NaNO}_{3}$ as solvent. A differential refractometer and an ultraviolet photometer (at $280 \mathrm{~nm}$ ) were used as detectors, and the elution volume was corrected to the internal marker of ethylene glycol at $11.25 \mathrm{~mL}$. Pullulan samples (Shodex Denko) of $M_{\mathrm{w}} 5.9 \times 10^{3}$, $1.18 \times 10^{4}, 4.73 \times 10^{4}, 2.12 \times 10^{5}$ and $7.88 \times 10^{5}$ $\mathrm{g} / \mathrm{mol}$ were used as standards (Melo et al., 2002).

\section{Experimental protocols In vitro duodenum contractility}

Tissue preparations: Male Wistar rats (250-350 g, $n=6)$ were initially killed by cervical dislocation. A 2-cm long whole segment of the proximal rat duodenum was removed and placed into a Petri dish containing Tyrode's solution (composition in mmol/l: $\mathrm{NaCl}: 136.9 ; \mathrm{KCl}: 2.68 ; \mathrm{MgCl}_{2}$ : 1.05; $\mathrm{CaCl}_{2}: 1.8 ; \quad \mathrm{NaH}_{2} \mathrm{PO}_{4}: \quad 0.42 ; \quad \mathrm{NaHCO}_{3}: 11.9$; glucose: 5.55). After the dissection of mesentery muscle, the luminal contents were washed with physiological solution. The duodenal segments were placed under 1-g resting tension in a glass organ bath filled with $10 \mathrm{ml}$ of Tyrode's solution. The solution was maintained at $37^{\circ} \mathrm{C}(\mathrm{pH} 7.4)$ and bubbled continuously with air. Longitudinal muscle tension was recorded on a computercoupled data-acquisition system (Power-Lab, ADInstruments ${ }^{\mathrm{TM}}$, Australia) by means of an isometric force transducer. It was left for one hour for equilibration. Initially, the concentrationresponse curves at the concentrations of $0.5,1,2$, 4,8 , and $16 \mu \mathrm{g} / \mathrm{ml}$ for the polysaccharides of $H$. floresia (Hf2s) were obtained and added cumulatively to the bath chamber ( 5 min for each concentration or, whenever necessary, $10 \mathrm{~min}$ to observe the plateau response). The difference between the peak and valley records at plateau contraction in the presence of polysaccharide was considered as the maximal effect of polysaccharide-induced contraction. The polysaccharide activity was also tested in the presence of atropine $(1 \mu \mathrm{M})$, a muscarinic receptor antagonist, to evaluate the effect of acetylcholine on the duodenal contractile responses to the polysaccharide. In order to evaluate the possible role of extracellular $\mathrm{Ca}^{2+}$ effect on the 
polysaccharide responses, verapamil $\left(10^{-6} \mathrm{M}\right)$, a voltage-gated $\mathrm{Ca}^{2+}$ channel blocker, or a $\mathrm{Ca}^{2+}$-free medium was used. To verify tissue vitality, the duodenal spontaneous contractile were tested 30 min after the polysaccharide removal (Clemente et al., 2008).

\section{In vivo gastric compliance (GC)}

Experiments were performed on the male Wistar rats (250-300 g, $n=22$ ), fasted for $24 \mathrm{~h}$ with access to water ad libitum. After urethane anesthesia (1.2 $\mathrm{g} / \mathrm{kg}$ ), the cervical vessels were surgically exposed, and cannulated with polyethylene catheters (PE 50) filled with saline and heparin $(500 \mathrm{U} / \mathrm{ml})$. The left jugular vein was used for polysaccharide, drugs, or vehicle administration. To evaluate the effect of Hf2s on GC, a latex balloon catheter $(\sim 4.0 \mathrm{ml})$ was introduced per se and then positioned in the proximal stomach of the rats. The catheter-free end was connected to a barostat liquid reservoir $(\mathrm{DI}=2.5 \mathrm{~cm}$, volume $=30$ $\mathrm{ml})$. The resulting communicant vessel system was filled with an ionic standard solution $(45 \mathrm{mg} \%$ of $\mathrm{NaCl}$ and $0.3 \mathrm{ml} \%$ of Imbebient BBC Ornano ${ }^{\circledR}$ ). The solution was pre-warmed and kept at $37^{\circ} \mathrm{C}$. The barostat liquid level was set at $4.0 \mathrm{~cm}$ above the animal's xiphoid appendix. The gastric tonus that changed the gastric balloon volume was electronically sensored and continuously displayed by a digital plethysmometer (LE 7500-PanLab ${ }^{\circledR}$ ) (Clemente et al., 2008). Following a basal period of $20 \mathrm{~min}$, the animals received (i.v.) polysaccharide $(20 \mathrm{mg} / \mathrm{kg})$ or vehicle $(0.2 \mathrm{ml}$ of $0.9 \%$ saline). Subsequently gastric volume was monitored for a 50 -min period, divided into five consecutive 10-min intervals.

\section{Statistical analysis}

The data were reported as mean \pm S.E.M. Analysis of variance (ANOVA) followed by the Student's $t$ test and Dunnett's test were employed to compare the differences between the basal and experimental values. A value of $P<0.05$ was considered significant.

\section{RESULTS AND DISCUSSION}

The H. floresia SPs have been recently extracted. This species is rich in three crude soluble SPs fractions (Hf1s, Hf2s and Hf3s), and they differ in molar ratios of sulfate/galactose (Amorim et al.,
2011). Fraction Hf2s contained the highest sulfate content $(53.08 \%)$. Besides, the anticoagulant activity of the three crude fractions measured by APTT test increased with the sulfate content. The chemical composition showed that Hf2s was composed of 6-O-metylgalactose and 3,6anhydrogalactose. Here, to further evaluate other characteristics of $H$. floresia polysaccharides, Hf1s, Hf2s and Hf3s were tested by agarose gel electrophoresis procedure. These fractions were also analyzed by GPC, and only Hf2s was used on the biological assays of the gastrointestinal system.

\section{Agarose gel electrophoresis}

The electrophoretic profile is presented in Fig. 1. Agarose gel electrophoresis showed differences in resolution degree among the isolated crude SP fractions. Hf1s and Hf2s showed more homogeneous bands, with weak metachromasia and, Hf3s showed a poly-disperse polysaccharide with metachromasia intense. These differences in charge density of these algal molecules in were accordance with other studies (Assreuy et al., 2008; Rodrigues et al., 2009b). This suggested that the $H$. floresia polysaccharides occurred with distinct molecular characteristics in the algal tissue. In this way, these physico-chemical characteristics could perhaps be indicative of an important role that these macromolecules exerted on their ionic, mechanical and osmotic functions in marine algae (Kloareg and Quatrano, 1988). According to Rodrigues et al. (2009b, 2010), the technique of successive extractions could be a valuable tool for the identification of molecular characteristics among different algal species and new biological agents.

\section{Molar mass distribution}

The GPC chromatograms of Hf1s, Hf2s and Hf3s are shown in Fig 2. All the fractions presented large MM distributions. Fraction Hf1s showed four peaks of MM with elution at 6.67, 8.82, 9.95 and $10.50 \mathrm{ml}$ when detected by refractive index measurements (Fig. 2A). In respect to $\mathrm{Hf} 2 \mathrm{~s}$ and Hf3s, three different peaks of MM (I, II and II) were noted, with elution volume at 7.57, 10.12 and $10.69 \mathrm{ml}$, and respectively, $6.62,8.19$ and 10.02 $\mathrm{ml}$ (Figs 2B and 2C). Therefore, the peaks obtained in Hf1s, Hf2s and Hf3s ranged from $8.0 \times$ $10^{2}$ to $5.0 \times 10^{6} \mathrm{~g} / \mathrm{mol}$.

These results suggested that $H$. floresia Hf2s behaved as heterogeneous system similar to other natural polysaccharides identified from Gracilaria 
cornea (Rhodophyta) (Melo et al., 2002) and Ulva rotundata (Chlorophyta) (Robic et al., 2009). In fact, algae polysaccharides have MM average and with the distribution of molecular species similar in its structures, but their variations occur in the same backbone polysaccharide size (Stephen, 1995).

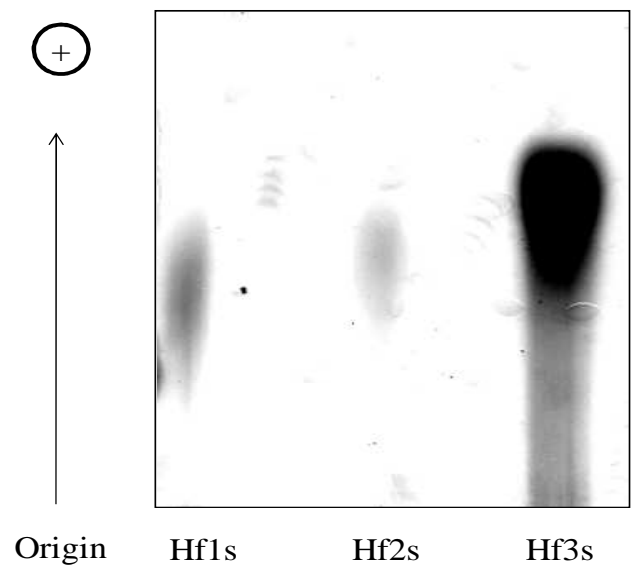

Figure 1 - Agarose gel electrophoresis of sulfated polysaccharides isolated from $H$. floresia. Fractions Hf1s, Hf2s and Hf3s present on gel were stained with $0.1 \%$ toluidine blue.
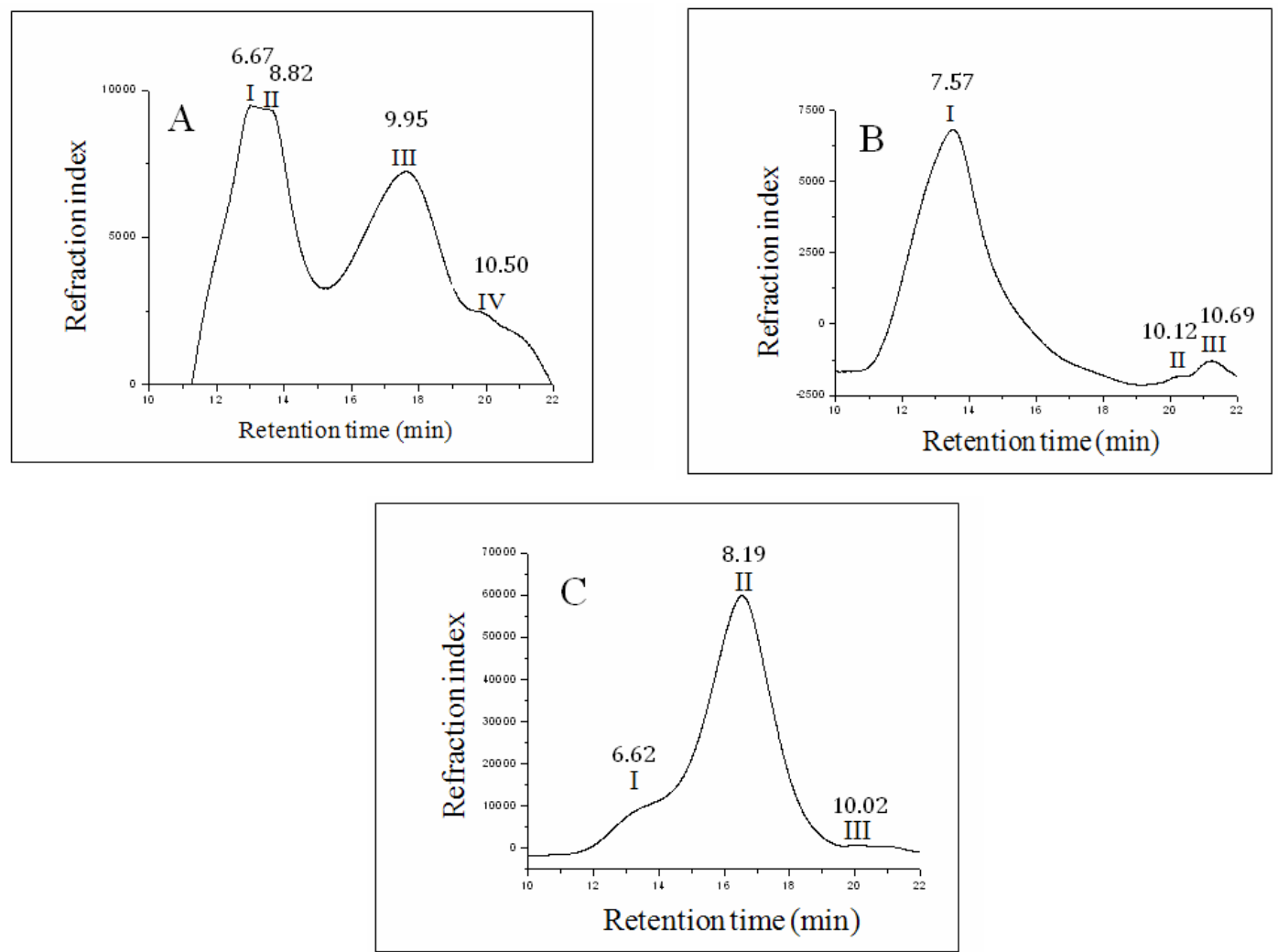

Figure 2 - GPC curves of fractions Hf1s (A), Hf2s (B) and Hf3s (C) for $H$. floresia in $0.1 \mathrm{M} \mathrm{NaNO}_{3}$ solution. 


\section{Biological assays}

In recently years, diverse biological activities have been focused for algae SPs (Nishino et al., 1991; Farias et al., 2000; Matsubara et al., 2001;

Mourão, 2004; Talarico et al., 2004; Pereira et al., 2005; Pushpamali et al., 2008; Rodrigues et al., 2009b; Rodrigues et al., 2010; Rodrigues et al., 2011a). These studies suggested that was interesting to investigate this class of macromolecules in animal models (Mourão and Pereira, 1999; Farias et al., 2001; Zhang et al., 2003; Assreuy et al., 2008; Fonseca et al., 2008; Lins et al., 2009; Ananthi et al., 2010), as valuable tools on development of new pharmacological drugs. The anticoagulant activity of marine algae SPs has been widely reported. Their actions are well described (Farias et al., 2000; Pereira et al., 2005; Fonseca et al., 2008; Rodrigues et al., 2010). Although not determinant for their biological actions (Leite et al., 1998; Farias et al., 2000; Pereira et al., 2005; Fonseca et al., 2008;
Rodrigues et al., 2009b), it has been accepted that the bioactivity of these compounds has positive correlation to sulfate group content (Nishino et al., 1991; Azevedo et al., 2009; Mestechkina and Shcherbukhin, 2010) and molecular weight distribution (Zhang et al., 2008; Azevedo et al., 2009; Mestechkina and Shcherbukhin, 2010).

Based on these hypotheses, in the present study, the effect of a crude SP fraction (Hf2s) isolated from $H$. floresia on in vitro and in vivo models of gastrointestinal system in rats was studied. Due to the high yield and sulfate content (Amorim et al., 2011), the Hf2s homogeneous fraction (Fig. 1) was used for these biological assays. The possible effect of Hf2s from the marine red algae $H$. floresia on intestinal contractile behavior using rat duodenal preparations in vitro was studied. The Hf2s demonstrated a concentration-dependent myocontractile effect on the rat duodenum with an $\mathrm{EC}_{50}$ value of $12.48 \mu \mathrm{g} / \mathrm{ml}(8-16 \mu \mathrm{g} / \mathrm{ml})$ (Fig. 3).

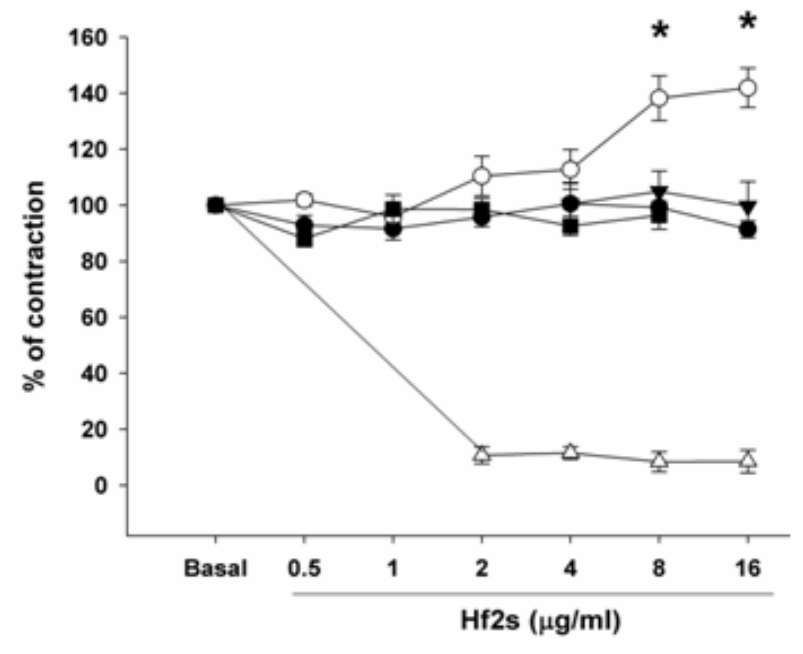

Figure 3 - Myocontractile effect of the sulfated polysaccharide from the marine red algae Halymenia floresia (Hf2s) on spontaneous contractions of rat-isolated duodenal in vitro preparations. Concentration-response curves at $0.5,1,2,4,8$, and $16 \mu \mathrm{g} / \mathrm{ml}$ for the polysaccharides of $\mathrm{Hf} 2 \mathrm{~s}$ were cumulatively added to the bath chamber. The graph shows the mean values of the effects of vehicle Tyrode $(\bullet, n=6)$, Hf2s $(\bigcirc, n=13)$, Tyrode $\mathrm{Ca}^{2+}$-free $(\boldsymbol{\nabla}, n=6)$, Tyrode + verapamil $(\triangle, n=6)$ or Tyrode + atropine $(\boldsymbol{\square}$, $n=6$ ), and SEM (vertical lines). $* P<0.05$ vs. basal interval (ANOVA and Dunnett's test).

Moreover, the inhibitory effect of Hf2s was observed to be reversible after consecutive washings. Interestingly, Hf2s, over the concentration range used in this study $(0.5-16$ $\mu \mathrm{g} / \mathrm{ml})$ did not produce spasmodic effects.
As the extracellular $\mathrm{Ca}^{2+}$ influx through the voltage-gated $\mathrm{Ca}^{2+}$ channels played an important role in gastrointestinal smooth muscle contraction (Clemente et al., 2008), the duodenal strips were pretreated with verapamil $(1 \mu \mathrm{M})$, an inhibitor of 
voltage-gated $\mathrm{Ca} 2+$ channels. In addition, the response of this muscle to $\mathrm{Hf} 2 \mathrm{~s}$ in a $\mathrm{Ca}^{2+}$-free medium was investigated. Verapamil was observed to completely inhibit the Hf2s-elicited contractile response in the duodenum strips, and only partially diminished the phasic response, which suggested that the Hf2s-elicited contractile response depended on the release of internal $\mathrm{Ca}^{2+}$ entry from the extracellular space through voltagedependent $\mathrm{Ca}^{2+}$ channels. Similarly, when the strips were incubated in $\mathrm{Ca}^{2+}$-free medium, the Hf2s contractile response was prevented. These results suggested that the inhibition of the influx of extracellular $\mathrm{Ca}^{2+}$ as well as the L-type $\mathrm{Ca}^{2+}$ channels blocked by verapamil could contribute to elucidate the Hf2s effects on rat duodenum contractile response.

To investigate the participation of muscarinic receptors in producing Hf2s effects, the strips were pretreated with atropine $(1 \mu \mathrm{M})$, a muscarinic receptor antagonist. Atropine pretreatment was observed to prevent the Hf2s myocontractile effect, which suggested the involvement of muscarinic acetylcholine receptors in the mediation of $\mathrm{Hf} 2 \mathrm{~s}$ contractile response in rat duodenum (Fig. 3). In this regard, it was observed that in $\mathrm{Ca}^{2+}$-containing solution, acetylcholine elicited similar concentration-dependent contractile responses in the duodenum, jejunum, and ileum strips of rat intestine. However, in $\mathrm{Ca}^{2+}$ free medium, acetylcholine induced phasic contractions that depended on the release of this ion from internal stores by the activation of the sarcoplasmatic-operated $\mathrm{Ca}^{2+}$ channels (Elorriaga et al., 1996).

Gastric emptying results from the integrated contractions of the proximal stomach, distal stomach, pylorus, and duodenum (Wingate et al., 1994). Gastric distension enhances gastric compliance (GC), which could be part of the homeostatic process to balance blood volume(Gondim et al., 2001; Graça et al., 2002). In this study, the effects of Hf2s on GC in urethane-anesthetized rats was also investigated. Figure 4 showed that 30 min after a basal interval, Hf $2 \mathrm{~s}$ treatment decreased the GC (from $3.8 \pm 0.06$ to $3.4 \pm 0.13 \mathrm{ml}, P<0.05$ ), and after over $50 \mathrm{~min}$, the $\mathrm{GC}$ did not return to the basal levels $(3.22 \pm 0.18$ $\mathrm{ml})$.

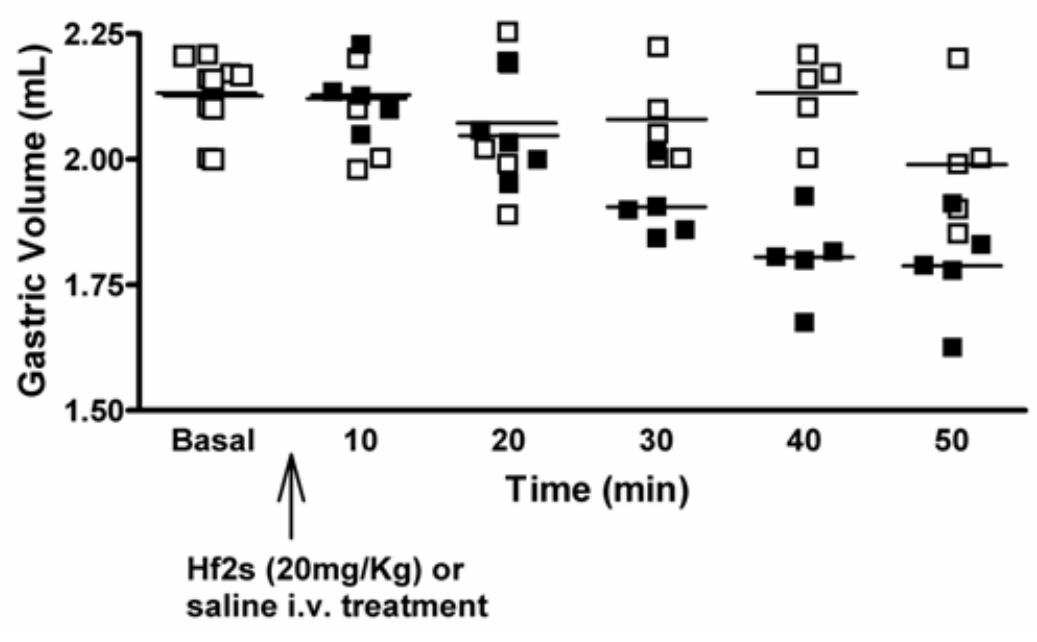

Figure 4 - Effect of the sulfated polysaccharide from the marine red algae Halymenia floresia (Hf2s) on the gastric volume (ml) in anesthetized rats. After $20 \mathrm{~min}$ (basal interval, untreated period), the animals were submitted to Hf2s $(20 \mathrm{mg} / \mathrm{kg}, n=6$, $\mathbf{\square})$ or vehicle (saline $0.9 \%, n=6, \square$ ) to i.v. administration. Gastric volume $(\mathrm{ml})$ data recorded by plethysmography were obtained before (basal interval) and $50 \mathrm{~min}$ after the treatments. Each value (white and black squares) pooled into consecutive 10-min intervals are presented as scatter, and a horizontal line represents the median. $* P<0.05$ vs. saline group (ANOVA and Dunnett's test). 
In conclusion, results showed for the first time that a sulfated galactan isolated from the marine red algae $H$. floresia had promising effects on GI motor functions, which included myocontractile effect on rat duodenum and decreased GC, suggesting that the stimulatory effects of $\mathrm{Hf} 2 \mathrm{~s}$ depended on the normal activity of the voltagegated $\mathrm{Ca}^{2+}$ channels and $\mathrm{Ca}^{2+}$ availability. Taken together, these data indicated that Hf2s could be useful when gastrointestinal contraction was necessary during motility-related disorders, and the red marine algae $H$. floresia could be a valuable and interesting natural source of bioactive compound potentially useful.

\section{ACKNOWLEDGMENTS}

This study was supported by the grants from the National Scientific and Technological Development Council (CNPq), Northeast Biotechnology Network (RENORBIO), Coordination for the Improvement of Higher Education Personnel (CAPES) and Ceará State Scientific and Technological Development Foundation (FUNCAP). PAULA, R.C.M. and BENEVIDES, N.M.B. are senior investigators of CNPq/Brazil.

\section{REFERENCES}

Amorim, R.C.N.; Rodrigues, J.A.G.; Holanda, M.L.; Mourão, P.A.S. and Benevides, N.M.B. (2011), Anticoagulant properties of a crude sulfated polysaccharide from the red marine alga Halymenia floresia (Clemente) C. Agardh. Acta Scien. Biol. Scien., 33, 255-261.

Ananthi, S.; Raghavendran, H.R.B.; Sunil, A.G.; Gayathri, V.; Ramakrishnan, G. and Vasanthi, H.R. (2010), In vitro antioxidant and in vivo antiinflammatory potential of crude polysaccharide from Turbinaria ornata (Marine Brown Alga). Food Chem. Toxicol., 48, 187-192.

Andrade, L.R.; Leal, R.N.; Noseda, M.; Duarte, M.E.R.; Pereira, M.S.; Mourão, P.A.S.; Farina, M. and Filho, G.M.A. (2010), Brown algae overproduce cell wall polysaccharides as a protection mechanism against the heavy metal toxicity. Mar. Poll. Bull., 60, 14821488.

Aquino, R.S.; Landeira-Fernandez, A.M.; Valente, A.P.; Andrade, I.R. and Mourão, P.A.S. (2005), Occurrence of sulfated galactans in marine angiosperms: evolutionary implications. Glycobiol., 15, 11-20.
Assreuy, A.M.S.; Gomes, D.M.; Silva, M.S.J.; Torres, V.M.; Siqueira, R.C.L.; Pires, A.F.; Criddle, D.N.; Alencar, N.M.N.; Cavada, B.S.; Sampaio, A.H. and Farias, W.R.L. (2008), Biological effects of a sulfated-polysaccharide isolated from the marine red algae Champia feldmannii. Biol. Pharm. Bull., 31, 691-695.

Bechère, E. (2000), Shrimp immunity and disease control. Aquacult., 191, 3-11.

Azevedo, T.C.G.; Bezerra, M.E.B.; Santos, M.G.L.; Souza, L.A.; Marques, C.T.; Benevides, N.M.B. and Leite, E.L. (2009), Heparinoids algal and their anticoagulant, hemorrhagic activities and platelet aggregation. Biom. Pharmacoth. 63, 477-483.

Campo, V.L.; Kawano, D.F.; Silva, D.B. and Carvalho, I. (2009), Carrageenans: Biological properties, chemical modifications and structural analysis - A review. Carbohydr. Polym., 77, 167-180.

Carvalho, A.F.U.; Portela, M.C.C.; Sousa, M.B.; Martins, F.S.; Rocha, F.C.; Farias, D.F. and Feitosa, J.P.A. (2009), Physiological and physico-chemical characterization of dietary fiber from the green seaweed Ulva fasciata Delile. Braz. J. Biol., 69, 969977.

Clemente, C.M.; Araújo, P.V.; Palheta-Jr, R.C.; Rattsa, Z.M.L.; Fernandes, G.H.; Rola, F.H.; Oliveira R.B.; Santos, A.A. and Magalhães, P.J.C. (2008), Sildenafil inhibits duodenal contractility via activation of the NO-K+ channel pathway. Fundam. Clin. Pharmacol., 22, 61-67.

Dietrich, C.P. and Dietrich, S.M.C. (1976), Electrophoretic behavior of acidic mucopolysaccharides in diamine buffers. Anal. Biochem., 70, 645-647.

Elorriaga, M.; Anselmi, E.; Hernandez, J.M.; D'Ocon, P. and Ivorra, D. (1996), The sources of Ca2+ for muscarinic receptor-induced contraction in the rat ileum, J. Pharm. Pharmacol., 48, 817-819.

Farias, W.R.L.; Valente, A.P.; Pereira, M.S. and Mourão, P.A.S. (2000), Structure and anticoagulant activity of galactans: isolation of a unique sulfated galactan from the red algae Botryocladia occidentalis and comparison of its anticoagulant action with that of sulfated galactans from invertebrates. J. Biol. Chem., 275, 29299-29307.

Farias, W.R.L.; Nazareth, R.A. and Mourão, P.A.S. (2001), Dual effects of sulfated D-galactans from the red alga Botryocladia occidentalis thrombosis and inducing platelet aggregation. Thromb. Haemost., 86, 1540-1546.

Fonseca, R.J.C.; Oliveira, S.N.M.C.G.; Melo, F.R.; Pereira, M.G.; Benevides, N.M.B. and Mourão, P.A.S. (2008), Slight differences in sulfatation of algal galactanas account for differences in their anticoagulant and venous antithrombotic activities. Throm. Haemost., 99, 539-545. 
Gondim, F.A.; Rodrigues, C.L.; Graça, J.R.; Camurça, F.D.; Alencar, H.M.; Santos, A.A. and Rola F.H. (2001), Neural mechanisms involved in the delay of gastric emptying and gastrointestinal transit of liquid after thoracic spinal cord transection in awake rats. Auton Neurosc., 87, 52-58.

Graça, J.R.; Leal, P.R.; Gondim, F.A.; Rola, F.H. and Santos, A.A. (2002), Variations in gastric compliance induced by acute blood volume changes in anesthetized rats. Braz. J. Med. Biol. Res., 35, 405410.

Hayashi, K.; Hayashi, T. and Kojima, I. (1996), A natural sulfated polysaccharide, calcium spirulan, isolated from Spirulina platensis: in vitro and ex vivo evaluation of anti-herpes simplex virus and antihuman immunodeficiency virus activities. Aids Res. Hum. Retrov., 12, 1463-1471.

Kloareg B. and Quatrano R.S. (1988), Structure of the cell wall of marine algae and ecophysiological functions of matrix polysaccharide. Oceanogr. Mar. Biol. Ann. Rev., 26, 29299-29307.

Langwinski, D. and Patiño, H.O. (2001), A nutrição de ruminantes e os complexos orgânicos de minerais. Tortuga, São Paulo.

Leite, E.L.; Medeiros, M.G.L.; Rocha, H.A.O.; Farias, G.G.M.; Silva, L.F.; Chanvante, S.F.; Abreu, L.D.; Dietrich, C.P. and Nader, H.B. (1998), Structure and pharmacological activities of a sulfated xylofucoglucuronan from the alga Spatoglossum schröederi. Plant Science. 132, 215-278.

Li, N.; Zhang, Q. and Song, J. (2005), Toxicological evaluation of fucoidan extracted from Laminaria japonica in Wistar rats. Food Chem. Toxicol., 43, 421-426.

Lins, K.O.A.L.; Bezerra, D.P.; Alves, A.P.N.; Alencar, N.M.N.; Lima, M.W.; Torres, V.M.; Farias, W.R.L.; Pessoa, C.; Moraes, M.O. and Costa-Lotufo, L.V. (2009), Antitumor properties of a sulfated polysaccharide from the red seaweed Champia feldmannii (Diaz-Pifferer). J. Appl. Toxocol., 29, 2026.

Marinho-Soriano, E. (2006), Seasonal variation in the chemical composition of two tropical seaweeds. Biores. Technol., 97, 2402-2406.

Matsubara, K.; Matsubara, Y.; Basic, A.; Liao, M.L. and Hori, K. (2001), Anticoagulant properties of a sulfated galactan preparation from a marine green alga, Codium cylindricum. Inter. J. Biol. Macromol., 28, 395-399.

Mestechkina, N.M. and Shcherbukhin,V.D. (2010), Sulfated polysaccharides and their anticoagulant activity: A review. Appl. Biochem. Microbiol., 46, 291-298.

Mourão, P.A.S. (2004), Use of sulfated fucans as anticoagulant and antithrombotic agents: future perspectives. Curr. Pharm. Des., 10, 967-981.
Morales, J.L.; Cantillo-Ciau, Z.O.; Sánchez-Molina, I. and Mena-Rejón, G.J. (2006), Screening of antibacterial and antifungal activities of six marine macroalgae from coasts of Yucatán Peninsula. Pharm. Biol., 44, 632-635.

Mourão, P.A.S. and Pereira, M.S. (1999), Searching for alternatives to heparin: sulfated fucans from marine invertebrates. Tren. Cardiov. Med., 9, 225-232.

Melo, M.R.S.; Feitosa, J.P.A.; Freitas, A.L.P. and Paula, R.C.M. (2002), Isolation and characterization of soluble sulfated polysaccharide from the red seaweed Gracilaria cornea. Carbohydr. Polym., 49, 491-498.

Nishino, T.; Aizu, Y. and Nagumo, T. (1991), The influence of sulfated content and molecular weight of a fucan sulfate from the brown seaweed Ecklonia kurome. Thromb. Res., 64, 723-731.

Pereira, M.G.; Benevides, N.M.B.; Melo, M.R.S.; Valente, A.P.; Melo, F.R. and Mourão, P.A.S. (2005), Structure and anticoagulant activity of a sulfated galactan from the red alga, Gelidium crinale. Is there a specific structural requirement for the anticoagulant action? Carbohydr. Res., 340, 2015-2023.

Pires, K.M.S.; Alencar, D.B.; Sousa, M.B.; Sampaio, A.H. and Saker-Sampaio, S. (2008), Teores de $\alpha$ caroteno e $\beta$-caroteno em macroalgas marinhas desidratadas. Rev. Ciên. Agron.. 39, 257-262.

Pomin, V.H. and Mourão, P.A.S. (2008), Structure, biology, evolution, and medical importance of sulfated fucans and galactans. Glycobiol., 18, 10161027.

Pushpamali, W.A.; Nikapitiya, C.; Zoysa, M.D.; Whang, I.; Kim, S.J. and Lee, J. (2008), Isolation and purification of an anticoagulant from fermented red seaweed Lomentaria catenata. Carbohydr. Polym., 73, 274-279.

Robic, A.; Rondeau-Mouro, C.; Sassi, J.F.; Lerat, Y. and Lahaye, M. (2009), Structure and interactions of ulvan in the cell wall of the marine green algae Ulva rotundata (Ulvales, Chlorophyta). Carbohydr. Polym., 77, 206-216.

Rodrigues, J.A.G.; Vanderlei, E.S.O.; Queiroz, I.N.L.; Quinderé, A.L.G. and Benevides, N.M.B. (2009a), Purificação e atividade anticoagulante de glicosaminoglicanos isolados da pele da carpa comum, Cyprinus carpio. Rev. Ciên. Agron., 40, 381387.

Rodrigues, J.A.G.; Torres, V.M.; Alencar, D.B.; Sampaio, A.H. and Farias, W.R.L. (2009b), Extração e atividade anticoagulante dos polissacarídeos sulfatados da alga marinha vermelha Halymenia pseudofloresia. Rev. Ciên. Agron., 40, 224-231.

Rodrigues, J.A.G.; Torres, V.M.; Alencar, D.B.; Sampaio, A.H. and Farias, W.R.L. (2010), Heparinoides naturais isolados de rodofíceas (Halymenia sp.) arribadas na costa cearense. Acta. Scien. Biol. Scien., 32, 235-242. 
Rodrigues, J.A.G.; Araújo, I.W.F.; Paula, G.A.; Lima, T.B.; Bessa, E.F. and Benevides, N.M.B. (2011a), Carragenana da epífita Hypnea musciformis obtida do cultivo experimental de Solieria filiformis em Flecheiras, Estado do Ceará, Brasil. Acta. Scien. Technol., 33, 137-144.

Rodrigues, J.A.G.; Queiroz, I.N.L.; Bessa, E.F.; Coura, C.O.; Amorim, R.C.N. and Benevides, N.M.B. (2011b), Anticoagulant activity of sulfated polysaccharides fractions from an aqueous extract obtained from the red seaweed Halymenia floresia (Clemente) C. Agardh. Acta Scien. Technol., 33, 371378.

Silva, F.R.F.; Dore, C.M.P.G.; Marques, C.T.; Nascimento, M.S.; Benevides, N.M.B.; Rocha, H.A.O.; Chavante, S.F. and Leite, E.L. (2010), Anticoagulant activity, paw edema and pleurisy induced carrageenan: Action of major types of commercial carrageenans. Carbohydr. Polym., 79, 26-33.

Stephen, A.M. (1995), Food polysaccharides and their applications. Department of Chemistry, University of Cape Town, Rondebosch, South Africa. Marcel Dekker Inc. New York, USA, 1995.
Talarico, L.B.; Zibetti, R.G.M.; Faria, P.C.S.; Scolaro, L.A.; Duarte, M.E.R.; Noseda, M.D.; Pujol, C.A.and Damonte, E.B. (2004), Anti-herpes simplex virus activity of sulfated galactans from the red seaweeds Gymnogongrus griffithsiae and Cryptonemia crenulata. Inter. J. Biol. Macromol., 34, 63-71.

Wingate, D. L.; Stacher, G. and Kreiss, C. (1994), Role and integration of mechanism controlling gastric emptying. Dig. Diseas. Scien., 39, 120-123.

Zhang, Q.B.; Li, N.; Zhou, G.F.; Lu, X.L.; Xu, Z.H. and $\mathrm{Li}, \quad$ Z. (2003), In vivo antioxidant activity of polysaccharide fraction from Porphyra haitanesis (Rhodophyta) in aging mice. Pharmacol. Res., 48, 151-155.

Zhang, H.J.; Mao, W.J.; Fang, F.; Li, H.Y.; Sun, H.H.; Chen, Y. and Qi, X.H. (2008), Chemical characteristics and anticoagulant activities of a sulfated polysaccharide and its fragments from Monostroma latissimum. Carbohydr. Polym., 71, 428-434. 